\title{
Preparation of Star-Shaped Polylactic Acid Drug Carrier Nanoparticles
}

\author{
Michele Marini \\ Mazal-TOV S. A. S., Via Carmelitane Scalze - Modena, Italy. \\ Email: marini.michele@email.it \\ Received February $13^{\text {th }}, 2010$; revised March $13^{\text {th }}, 2010$; accepted March $15^{\text {th }}, 2010$.
}

\begin{abstract}
Drug carrier biocompatible and biodegradable nanoparticles of about $15 \mathrm{~nm}$ were prepared by solvent evaporation technique from star-shaped poly(D,L-lactide) synthesized using dipentaerythritol as core and Tin (II) ethylhexanoate as catalyst.
\end{abstract}

Keywords: PLA, Nanoparticles, Drug-Carriers

\section{Introduction}

It is well known that the penetration of substances into the brain is limited by the blood-brain barrier (BBB) which is formed by the endothelium of the brain vessels, the basal membrane and neuroglial cells [1]. Because of this most drugs do not pass the BBB. It is widely accepted that only compounds which are unionized at physiological $\mathrm{pH}$, are lipophilic, and of low molecular mass can cross the BBB by diffusion mechanisms, and other compounds, such as amino acids, neuropeptides, and hexoses, need specific carrier proteins to pass into the brain [1]. To overcome the limited access of drugs to the brain, several methods have been employed to achieve BBB penetration. The use of drug carriers such as liposomes [2] and nanoparticles for targeted drug delivery has been examined.

Biodegradable polymers have long been of interest in drug carriers and controlled release technology because of the ability of these polymers to be reabsorbed by the body [3]. This alleviates the need for removal, often surgically, of a drug release device. The most widely used and studied class of biodegradable polymers is the polyesters, including poly(lactic acid), poly(glycolic acid), and their copolymers and poly(lactic acid) (henceforth referred to as PLA) was investigated as a drug delivery material as early as 1971 [3].

There are a large number of research groups, worldwide, examining PLA in the form of microparticles and nanoparticles, for use in controlled drug delivery systems using a solvent evaporation technique, or modification thereof $[4,5]$. Although these references, there isn't any work in literature which reports the preparation of star- shaped PLA drug carrier nanoparticles.

In this work the synthesis of star-shaped PLA and the preparation of nanoparticles using a modified solvent evaporation method is reported.

\section{Experimental Part}

Star-shaped PLA was synthesized using dipentaerythritol (DPE) as core, D,L-dilactide (LA) as monomer and Tin (II) ethylhexanoate $\left(\mathrm{Sn}(\mathrm{Oct})_{2}\right)$ as catalyst [6] as reported in Scheme 1.

Monomer ( $5 \mathrm{~g}, 0.035 \mathrm{~mol})$ was added under nitrogen to a flame dried, $50 \mathrm{~mL}$ round-bottomed flask containing a magnetic stir bar and sealed with a rubber septum. The system was purged with nitrogen. Dipentaerythritol $(0.247 \mathrm{~g}, 0.00097 \mathrm{~mol})$ in toluene $(1 \mathrm{ml})$ was added via syringe under nitrogen. The reaction flask was immersed in a $130^{\circ} \mathrm{C}$ oil bath and sufficient time was allowed for the lactide and DPE to melt. A catalytic amount of $\mathrm{Sn}(\mathrm{Oct})_{2}(0.162 \mathrm{~g}, 0.0004 \mathrm{~mol})$ in toluene $(1 \mathrm{ml})$ was added, and the reaction mixture was allowed to stir for 10 $\min$. The reaction temperature was decreased to $120^{\circ} \mathrm{C}$, and the reaction was allowed to proceed for $24 \mathrm{~h}$. The product was dissolved in chloroform, precipitated in a hexane/methanol mixture (90:10), and dried in vacuo at $60^{\circ} \mathrm{C}$ for $24 \mathrm{~h}$.

Molecular weight and chemical structure of the star-shaped PLA were analyzed by ${ }^{1} \mathrm{H}-\mathrm{NMR}$. Nuclear magnetic spectra, performed with a Bruker FT Avance DPX200 instrument using $\mathrm{CDCl}_{3}$ as solvent and tetramethylsilane as internal reference, is reported in the following Figure 1.

Mn values was calculated by comparison of multiplet at $5 \mathrm{ppm}(\boldsymbol{a}, 1 \mathrm{H})$ with respect to the singolet at $4 \mathrm{ppm}(\boldsymbol{e}$, 


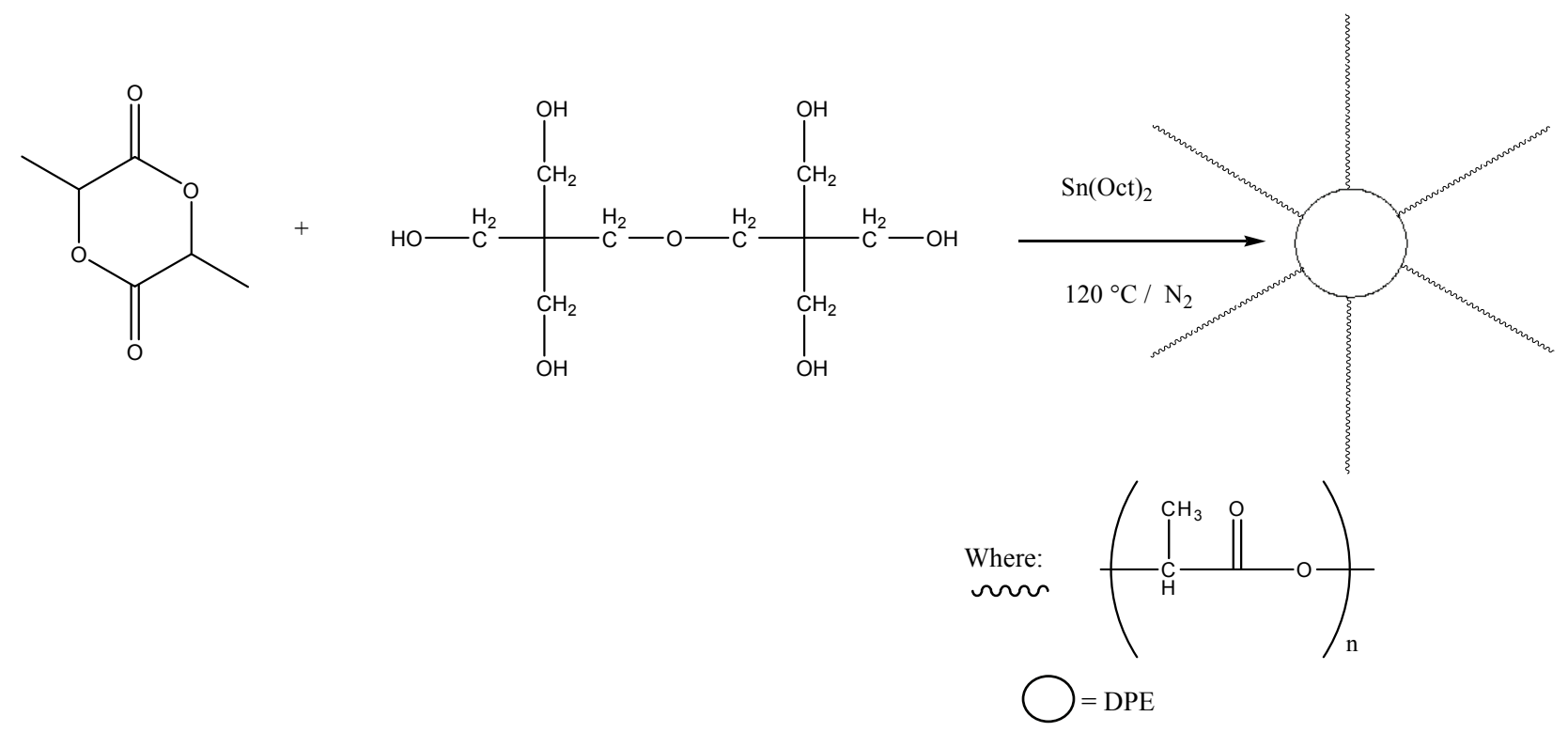

Scheme 1. Scheme of the synthesis of star-shaped PLA<smiles>CC(C)OC(C)C(CO)(CO)C(C)C(=O)OC(C)(C)C(=O)C(C)O</smiles>

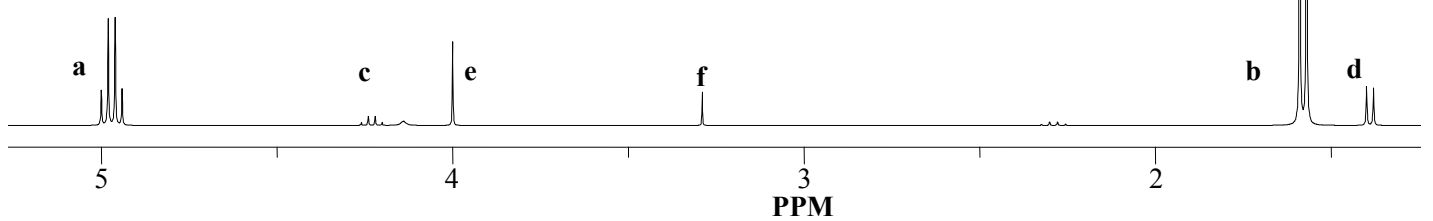

Figure 1. ${ }^{1} \mathrm{H}-\mathrm{NMR}$ of the star-shaped PLA and relative signal assignment

12H). A good agreement between the calculated $(\sim 5450$ $\mathrm{g} / \mathrm{mol})$ and the experimental $(\sim 5300 \mathrm{~g} / \mathrm{mol})$ molecular weight was found.

In order to determine molecular weights and its distribution gel permeation chromatography (GPC) using THF as solvent at $30^{\circ} \mathrm{C}$ was performed (relative Mark-Howink-Sakurada constants were used as reported in the literature [7]). A Waters instrument equipped by a Waters 1515 HPLC isocratic pump, a Mini-Mesopore (Polymer Laboratories) $250 \times 4.6 \mathrm{~mm} 5 \mu \mathrm{m}$ column and Waters 2410 refractive index detector was used. Molecular weights obtained from GPC (Mn and Mw of 4420 and 4810 respectively) are lower than the values calculated by ${ }^{1} \mathrm{H}-\mathrm{NMR}$, probably due to the star-shaped conformation of the macromolecules, which reduces dramatically the hydrodynamic volume of the polymer. A very narrow molecular weight distribution (a 1.101 of polydispersity index) was achieved.

Once the star-shaped PLA polymers were synthesized, the micelles nanoparticles were prepared by a solvent evaporation method [4,5]. Practically, star-shaped PLA was dissolved in ethyl acetate $(10 \mathrm{~mL})$ at the concentra- 
tions of $15 \% \mathrm{w} / \mathrm{v}$. This polymer solution was preemulsified using a disperser (Ultraturrax T18 basic, IKA) at $8000 \mathrm{rpm}$ for $5^{\prime}$ with $20 \mathrm{~mL}$ of an aqueous solution of sodium dodecyl sulfate $(2 \mathrm{~g} / \mathrm{L})$. Water $(80 \mathrm{ml})$ was subsequently added under magnetic stirring leading to the nanoprecipitation of the polymer.

The morphology of nanoparticles was observed using a JEOL JEM 2010 Transmission Electron Microscopy (TEM) equipped with a GIF Gatan Multiscan Camera and a microanalyzer EDS Inca 100. Photographs were obtained using transmission microscope at an accelerating voltage of $200 \mathrm{kV}$. The sample was prepared by dipping the TEM net in the previously described water solution. TEM micrographs of the PLA nanospheres are reported in Figure 2.

As it is possible to see a very narrow distribution of nanoparticles dimension was obtained, with an average diameter of $15 \pm 5 \mathrm{~nm}$.

\section{Conclusions}

In this preliminary work, the synthesis of star-shaped PLA and the preparation of nanoparticles using a modi-

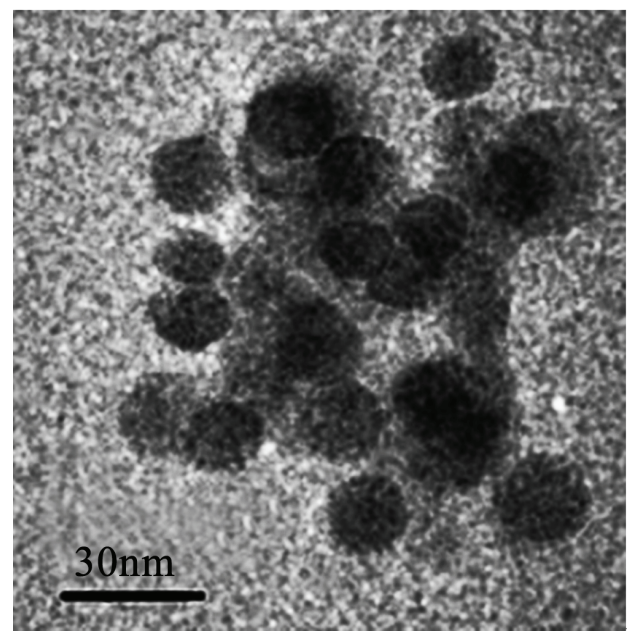

Figure 2. TEM images $(150 \mathrm{KX})$ of the micelle-like star-shaped PLA nanoparticles fied solvent evaporation method is reported. The prepared nanoparticles have average diameter of $15 \mathrm{~nm}$, much smaller than that of typical blood cells, such as erythrocytes or lymphocytes $(\sim 7-10 \mu \mathrm{m})$, hence may be injected into the bloodstream and used as drug carrier to pass the blood brain barrier (BBB). In a second work the efficiency of the nanoparticles as drug carriers will be studied.

\section{REFERENCES}

[1] U. Schröder and B. Sabel, "Nanoparticles, a Drug Carrier System to Pass the Blood-Brain Barrier Permit Central Analgesic Effects of i.v. Dalargin Injections," Brain Research, Vol. 710, 1996, pp. 121-124.

[2] X. Zhou and E. Huang, "Targeted Delivery of DNA by Liposomes and Polymers," Journal of Controlled Release, Vol. 19, 1992, pp. 269-274.

[3] A. Vila, A. Sanchez, M. Tobio, P. Calvo and M. J. Alonso, "Design of Biodegradable Particles for Protein Delivery," Journal of Controlled Release, Vol. 78, 2002, pp. $15-24$.

[4] A. Rouzes, M. Leonard, A. Durand and E. Dellacherie, "Influence of Polymeric Surfactants on the Properties of Drug-Loaded PLA Nanospheres," Coloids and Surfaces B: Biointerfaces, Vol. 32, 2003, pp. 125-135.

[5] S. Desgouilles, C. Vauthier, D. Bazile, J. Vacus, J. L. Grossiord, M. Veillard and P. Couvreur, "The Design of Nanoparticles Obtained by Solvent Evaporation: A Comprehensive Study," Langmuir, Vol. 19, 2003, pp. 9504 9510 .

[6] A. S. Karikari, W. F. Edwards, J. B. Mecham and T. E. Long, "Influence of Peripheral Hydrogen Bonding on the Mechanical Properties of Photo-Cross-Linked Star-Shaped Poly(D,L-lactide) Networks," Biomacromolecules, Vol. 6, 2005, pp. 2866-2874.

[7] W. Radke, K. Rode, A. V. Gorshov and T. Biela, "Chromatographic Behaviour of Functionalized Star-Shaped Poly(lactide)s under Critical Conditions of Adsorption. Comparison of Theory and Experiment," Polymer, Vol. 46, 2005, pp. 5456-5465. 